\title{
1 Assessing demand for improved sustainable sanitation in low-income 2 informal settlements of urban areas: A critical review
}

\begin{abstract}
Sanitation improvement is crucial in saving lives that are lost due to water contamination. Progress towards achieving full sanitation coverage is still slow in lowincome informal settlements in most developing countries. Furthermore, resources are being wasted on installing facilities that are later misused or never used because they do not meet the local demand. Understanding demand for improved sanitation in the local context is critical if facilities are to be continually used. Various approaches that attempt to change peoples' behaviours or create demand have been reviewed to identify what they are designed to address. A multi-disciplinary research team using mixed methods is re-emphasised as a comprehensive approach for assessing demand for improved sanitation in low-income informal settlements, where the sanitation situation is more challenging than in other areas. Further research involving a multi-disciplinary research team and use of mixed methods to assess sanitation demand in informal settlements is needed.
\end{abstract}

Key words: assessment, behaviour, demand, informal settlements, sanitation

\section{Introduction}

Poor sanitation and a lack of hygienic household practices is the major cause of water contamination along the supply chain, contributing to an estimated $88 \%$ of diarrhoeal deaths worldwide (UNICEF/WHO 2009). Despite interventions by governments and other partners, safe water and improved sanitation is still far from being realised, especially in peri-urban areas in developing countries where services tend to by-pass low-income informal settlements (UN-HABITAT 2011; UN 2011; WHO/UNICEF 2012). However, water has received more interventions and attention than sanitation (Clark and Gundry 2004) in meeting the Millennium Development Goal (MDG) target 7(c): to halve the proportion of people without sustainable access to safe drinking water and basic sanitation by 2015. Sub-Saharan Africa has the lowest level of improved sanitation coverage (30\%) of any region in the world, with no progress in urban areas (43\%) between 1990 and 2010 (WHO/UNICEF 2012). This raises the question as to why progress has been so slow in Sub-Saharan Africa. 
Informal settlements are defined residential areas situated on illegally occupied land or where housing is not in compliance with planning and building regulations (UN-HABITAT 2003), and have unique socio-economic, environmental, institutional and demographic challenges that are context specific in each local setting (Hogrewe et al. 1993; Foppen and Kansiime 2009; Lüthi et al. 2009). Provision of sanitation services in informal settlements is complex, with evidence that basic sanitation coverage is much lower compared to the average for urban areas (UN-HABITAT 2003; Foppen and Kansiime 2009). Where facilities exist, the majority are either shared (Tumwebaze et al. 2013), not clean, and not adequate enough to provide dignity and privacy (Van Der Geest 2002).

Efforts to improve access to sanitation have often focused on hardware interventions (Murray and Ray 2010; Van der Hoek et al. 2010), i.e. physical infrastructure that facilitates the safe management of human waste and includes toilets, sewers, water pipes, hand washing basins and other facilities along the sanitation waste flow-streams (Van Wyk 2009; Peal et al. 2010; Trémolet et al. 2010). Provision of sanitation facilities without considering the local demand may result in the facilities either being abandoned, misused or never used at all (Solo et al. 1993; Mara et al. 2010). This amounts to wastage of resources.

Sanitation interventions need to address the local demand to ensure that facilities built are used to realise their full public health benefits (Evans and Tremolet 2010). This approach requires the identification of "software" attributes necessary to support any sanitation hardware interventions, e.g. activities that focus on hygiene awareness and behaviour of the people so as to address the issues of why excreta-related health problems exist (Peal et al. 2010; Van der Hoek et al. 2010; Mosler 2012). Research has proved that it is useful to identify strategies for scaling-up sustainable coverage of improved sanitation (Varley et al. 1996; Jenkins and Sugden 2006; Robbins 2007; Lüthi et al. 2010; Mukherjee and Shatifan 2010) in low-income informal settlements. The slow progress in increasing coverage in informal settlements can partly be explained by the low demand for improved sanitation (Parry-Jones 1999; Evans 2004; Peal et al. 2010). Poor understanding of local demand can have different impacts. Communities select different excreta disposal practices based on traditional beliefs and cultural influences and are unlikely to use systems that conflict with these (WSP 2004; Van der Hoek et al. 2010). Some communities believe in excreting in the open either because of religion or being pastoralist (WSP 2004), and are unlikely to use hardware without specific software interventions to promote behaviour change. Understanding how sanitation demand is assessed and stimulated is critical to improving access (Isunju et al. 2011). 
This article aims to review the literature on approaches that attempt to change peoples' behaviour towards better defecation practices or to create demand for improved sanitation that is sustainable, and to recommend a sanitation demand assessment methodology for lowincome informal settlements to effect better informed planning of sanitation developments. We will first present the methods used to derived the reviewed literature and, review the definitions of some key issues in sanitation in the contexts of low-income informal settlements. We then relate the low progress on sanitation coverage to initiatives that may not be addressing the local demand for improved sanitation facilities. Barriers and catalysts for household demand for improved sanitation are then discussed and finally, a critical review of sanitation demand assessment methodologies is presented.

\section{Methods}

We developed a comprehensive search strategy to first identify articles using paired keyword search terms: sanitation, demand and assessment or behaviour; available in Web of Knowledge database. Initially, with no restriction on date of article publication, the search identified 940 articles containing a combination of at least two of the keywords. All titles of the identified articles were critically examined and only 12 peer-reviewed articles were considered to have relevant information for review. Full texts of the 12 selected peerreviewed articles were retrieved and information extracted for review.

Furthermore, references of the key peer-reviewed articles were scanned to identify other literature that can provide relevant information on the keywords. Titles and abstracts (if available) of the second lot of articles / documents selected from the key peer-reviewed articles were critically scanned to identify and select only those that can provide some relevant information on the keywords, for inclusion in the review. The secondary searched documents included other peer-reviewed articles, reports and other published papers that present information on behavioural change and sanitation demand assessment methodologies. Full text of the additional literature of original works cited in the initial peer-reviewed articles were retrieved and information on keywords extracted for review. Findings of the review guided in the development of research tools to assess sanitation demand in informal settlements of three cities in East African (Katrina \& Okurut 2013). Output from the research supports the recommendations for assessing demand for improved sustainable sanitation from the review. 


\section{Framing the key issues}

101

102

103

104

105

106

107

108

109

110

111

112

113

114

115

116

117

118

119

120

121

122

123

124

125

126

127

128

129

130

131

132

There are a number of contentious issues in the field of demand for improved sanitation including: the definition of improved sanitation, sanitation demand and behavioural change. The definition of these key issues have been framed from various definitions given in the literature and adopted throughout the paper to discuss the approaches that have been developed to change peoples' behaviour towards better defecation practices or to create demand for improved sanitation that is sustainable.

\section{Improved sanitation}

Sanitation has been defined in various ways (Evans 2004) based on the specific areas of concern but generally to mean the hygienic disposal or recycling of domestic wastes while promoting health through prevention of human contact with the hazardous wastes. The definition has been customised for the various types of waste streams and the extent along the waste flow streams. Hygienic disposal of human excreta and grey water at a household level is required to achieve a clean and healthy living environment. Sanitation includes the principles and practices of collection, removal or storage and disposal or re-use of human excreta with the concept of privacy and dignity from a human rights perspective (COHRE et al. 2008). Therefore, this article adopts the definition of improved sanitation developed by the Millennium Task Force as "access to, and use of excreta and wastewater facilities and services that ensure privacy and dignity, ensuring a clean and healthy living environment for all” (COHRE et al. 2008).

Where a sanitation facility can hygienically separate human excreta from human contact, the conditions of access, privacy, dignity and cleanliness may not be met if such a facility is shared by two or more households, or is a communal or public facility. The sharing of the facility compromises the social and public health benefits of the users (De Bruijne et al. 2007; COHRE 2009). Because of the shortfall of some social and public health factors, international debate is still open on whether shared or public sanitation facilities should be considered as "improved" (Günther et al. 2011). A study in Uganda reported that toilets shared with four households can be considered as improved sanitation based on visible cleanliness (Günther et al. 2012), yet the WHO / UNICEF Joint Monitoring Programme (JMP) considers such shared facilities as unimproved (WHO/UNICEF 2008). However, shared facilities will continue to fill the sanitation gap in informal settlements (Lüthi et al. 2009; WHO/UNICEF 2010; Günther et al. 2012; Tumwebaze et al. 2013) as they require 
relatively little space and only modest subsidies to achieve relatively high levels of coverage (Whittington et al. 1993).

\section{Sustainability}

Drawing from the work of Evans and Tremolet (2010) we contend that low-income informal settlements require sanitation service chains that are sustainable in terms of social, financial, and technological aspects. This will enable the community and individual households to provide affordable improvements to environmental health without continued external financial interventions in collection, emptying, transportation, treatment and disposal / re-use.

\section{Sanitation demand}

Household demand for improved sustainable sanitation is complex and is defined in a variety of ways drawing on psychological (Jenkins and Scott 2007), economic theory (Varley et al. 1996) and engineering (Parry-Jones 1999) aspects. It is influenced by a number of factors that include among others: demographic characteristics, availability, reliability, cost and convenience, and household attitudes (Parry-Jones 1999).

From the psychological perspective, Jenkins and Scott (2007) view demand for improved sanitation by a household as changing from a preference, when a household starts to develop preference for improved sanitation, to the intent to build, to the final stage of choosing from available options. Jenkins and Scott (2007) reasoned that demand for improved sanitation is an adoption decision process based on rational thinking and consumer purchase decision behaviour through preference for improved sanitation, intention and choice to change behaviour. The process, requires multiple operationalization of a number of methods for validation (Johnson et al. 2007) to ensure that the measured demand is a result of all the possible factors. Creswell and Clark (2007) note that the process involves both ontological and epistemological studies for systematic evaluation of the results and called it mixed method.

Varley et al. (1996) defines demand as an informed expression of willingness to pay (or give up in the form of other opportunities) at a given price (or opportunity cost) for the changes and improvements the person(s) want. Demand can also be expressed in terms of the time that a person is willing to spend on achieving personal or community objectives (Varley et al. 1996). Household demand for improved sanitation is an important social and 
behavioural process with implications for public health and may not have an apparent direct economic value to the householder (Hutton et al. 2007).

Through a review of the different definitions of demand for sanitation and considering sanitation as a social good, this paper defines demand for improved sanitation as an informed expression of willingness, and ability, to adapt to a new or better and appropriate sanitation service of preference. Beyond a household having preference for a better facility (user preference), there should be expressed willingness and ability to pay for and use the services that are considered appropriate for the area; only then can the household be counted to have demand for improvement.

\section{Behaviour change}

We define behaviour change as a psychological phenomenon where individuals, households or communities begin to act in some manner on specific aspects, on their own and do not depend on help from outside. Behaviour change is a complex process that could be as a result of several factors like changing awareness, consciousness, knowledge, attitudes and practice, norms and beliefs (Glanz and Bishop 2010). Mosler (2012) conceptualizes the driving factors into five main blocks as: risk, attitudinal, normative, ability, and selfregulation factors. A number of theories have been suggested to explain the process of behaviour change in public health (Bunton et al. 1991). Glanz and Bishop (2010) recognize the most often used theories as being social cognitive theory, health belief model, theory of planned behaviour and trans-theoretical model / stages of change.

Health belief and social cognitive theories consider self-induced action in response to a health situation either due to one's perception or external influences. Theory of planned behaviour, which is an extension of theory of reasoned action; asserts that behaviour changes come as a result of attitude, subjective norms and perceived control (Montano and Kasprzyk 2008). Trans-theoretical model proposes that people are at different stages of readiness to adopt healthful behaviours and integrates the processes and principles from across major theories in a sequence of six steps for a successful behaviour change: pre-contemplation (no recognition of need for or interest in change), contemplation (thinking about changing), preparation (planning for change), action (adopting new habits), maintenance (ongoing practice of new, healthier behaviour) and termination (Prochaska and Velicer 1997).

Human behaviour is guided by three kinds of considerations: beliefs about the likely outcomes of the behaviour, beliefs about the normative expectations of others, and motivation. The aggregate of these three considerations produce a favourable or unfavourable 
attitude to change one's behaviour that may eventually create demand for improvement (Ajzen 2002, 2006). The Trans-theoretical model for behaviour change and the household demand model for sanitation improvements are both complex change processes that involve multiples actions and adaptation along the sequential stages over time (Jenkins and Scott 2007; Glanz and Bishop 2010). It implies that creating demand for improved sanitation through a planned behavioural change decision process is likely to realise better results than imposing some practices on individual households. However, a number of factors can either motivate or demotivate the individual's decisions and the overall demand. These factors can be categorized as demand motivators and barriers respectively and are either permanent or temporary (Jenkins and Scott 2007).

\section{State of sanitation services in sub-Saharan Africa}

This section discusses the services along the sanitation chain and the stakeholders in the sanitation service sector. Sanitation chain refers to a series of linked stages in the management of human waste; in its transfer and transformation, as it passes through the various process steps, to its ultimate release into the environment (Tilley et al. 2008).

\section{Sanitation services and service providers}

The sanitation service is a set of activities involved in the improvement of sanitation along the sanitation chain right from the provision of resources for the installation / operation of sanitation systems to safe disposal / re-use. Such services may include among others; construction and / or operation of sanitation facilities, emptying, transportation, treatment, disposal / re-use and education / sensitisation on hygienic practices. Appropriate processes are different for formal and informal areas but in all cases the systems must be adapted to meet the needs of the user (Lüthi et al. 2009) and ensure that the waste doesn't get into human contact to avoid transmission of diseases. How this is achieved along the sanitation chain is equally important. The services that are needed in informal settlements include construction / installation of sanitation facilities, supply of sanitation products, repair / maintenance of facilities, emptying services, transportation / treatment / safe disposal of waste and, education / sensitisation of the community on hygienic practices.

There is insufficient private sector involvement in the sanitation sector because of lack of a commercial market, low creditworthiness and low potential for income generation (Van der Hoek et al. 2010; Trémolet 2012). On the other hand, key users of the services, and particularly women who are traditionally involved in the health of a household, are not aware 
of the services available (Outlaw et al. 2007). Noticing the mismatch, Murray and Ray (2010) suggest that sanitation intervention should then re-focus on the "back-end users" (like individual households) rather than "front-end users" (like suppliers of sanitary products), so that demand for sanitation services will trigger the supply, operation and maintenance of sanitation systems. This involves influencing human behaviour in a business approach by understanding consumers' needs, desires, habits, and circumstances as urged by Curtis et al. (2007) for the facility to be acceptable and meet the needs of the users rather than what fits them. However, a focus on only one side of the demand-supply market by either increasing the demand for sanitation services or availability of the services may create a mismatch that is likely to undermine sustainability of the sanitation services. How to assess the demand to be met before supplying any sanitation services is important because facilities supplied without considering the local demand have not been properly used (Peal et al. 2010).

Therefore, the community or individual household should be considered both as potential consumers and suppliers of sanitation services on the demand-supply market and their involvement and consideration in the sector can positively impact service delivery in informal settlements that mostly use on-site sanitation (Katukiza et al. 2012). The targeted community or individual households for any sanitation service should be consulted to ensure that the appropriate services are extended. Hence, the "front-end users" and "back-end users" should all be involved in a collective approach together with other key stakeholders in assessing the local demand for sanitation to ensure sustainability of sanitation services (Robbins 2007).

\section{Sanitation stakeholders}

There are several stakeholders involved in the sanitation sector such as national / international financers, service providers, consumer representatives, water resource and land management entities and health sector promoters acting at any point along the sanitation service chain with the intended users at the core of focus. As individual households often finance the processes involved in installing improved systems (Trémolet et al. 2010), efforts should involve them at all the stages of planning and implementation of sanitation interventions. Therefore, the challenge for all professionals is to work together, through dialogue, ideas exchange, and engagement with the individual households including the poor, to make pro-poor sanitation a reality (Paterson et al. 2007) in settlements with unique characteristics and many sanitation actors, and competing household demands (Van der Hoek et al. 2010). Since the impact of sanitation goes beyond the household and can affect the 
community and many other stakeholders (Moraes et al. 2003), a more collective approach is required to effectively manage the complex sanitation situation (Mara et al. 2010) in informal settlements with clearly defined roles for the different stakeholders along the sanitation chains. Mapping of such stakeholders' roles will improve the transfer of information to and communication with those who need the services most. However, engaging and understanding the views of stakeholders who come from different levels and perspectives by a single disciplinary research team may not maximise the inputs of these stakeholders.

The above argument highlights the need for a multi-disciplinary perspective to avoid biases in understanding the local demand for sanitation improvement from all the different stakeholder views to harmonise the feasibility of meeting the user preferences. Efforts can then be dedicated to facilitate the individual households to express their intent to install / upgrade an improved system and not just express their preferred facility.

\section{Initiatives to improve sanitation coverage}

Integrated approaches are required to increase the pace of progress on access to improved sanitation otherwise the world may have to wait until 2026 before the current MDG target on sanitation can be realised (WHO/UNICEF 2012). Many reasons have been suggested to explain the slow progress: technological, financial, regulatory, institutional, and political. But one aspect that stands out is that the conventional supply-led model has failed to generate demand for improved sanitation and behaviour change among targeted households (WSP 2001; Jenkins and Sugden 2006; Roma et al. 2010). If the local demand has not been adequately addressed in a project, actual usage of improved sanitation in informal settlements may be lower than the coverage that is reported (Mara et al. 2010).

Though sanitation delivery programs require software and hardware interventions, evidence in the developing world shows that the provision of facilities does not guarantee proper usage (Peal et al. 2010). There is a need to empower users with knowledge, enable a change in behaviour, create demand for services, facilitate establishment of supply chains, and improve the planning and implementation of hygiene and sanitation projects to go with appropriate hardware interventions (Evans 2004; Van Wyk 2009; Peal et al. 2010). The conventional supply-led approach in the developing world that prescribes the type of service suitable for a community is not applicable in informal settlements because of the formal standardized approaches that are not flexible to accommodate the unique characteristics of these settlements (Hogrewe et al. 1993; Varley et al. 1996; Samanta and Van Wijk 1998). Integrated approaches suggest the involvement of all key stakeholders along the sanitation 
service chain in the planning, implementation and management of sanitation projects (Varley et al. 1996; Paterson et al. 2007; Tiberghien et al. 2011) to meet the local demand and give the beneficiaries a sense of ownership, increasing its acceptance, usage and sustainability (Schertenleib 2001).

To increase sustainable access to sanitation requires that demand to install improved sanitation facility or upgrade to better sanitation facility must be created at the individual households (Jenkins and Sugden 2006; Kvarnström et al. 2011). Creating household demand requires an understanding of the unique characteristics of a community through the involvement of beneficiary households in demand assessment in order to identify appropriate solutions that will be sustainable.

Varley et al. (1996) suggest a Locally Based Demand (LBD) approach and also acknowledge that it emphasises demand considerations and ignores the interests of municipal and other government agencies responsible for environmental health services in peri-urban areas. Community Led Total Sanitation (CLTS) has been accepted and successful in some countries but its main objective is to stop open defecation and gives no opportunity for information provision on sanitation service providers (Mukherjee and Shatifan 2010). Though CLTS is used in rural areas where conditions are more favourable for its application (Kar and Chambers 2008), Practical Action is adopting CLTS in Nakuru slums. They are engaging stakeholders to help trigger residents and landlords alike to take action (Mwanzia and Misati 2013). However, little information is given on how residents' sanitation demand characteristics are assessed.

Community Health Clubs (CHC) is another initiative that can result in a huge demand for sanitation, however it's power relies on cohesiveness of a group and good neighbourliness (Waterkeyn and Cairncross 2005; Waterkeyn and Waterkeyn 2013). Both cohesiveness and good neighbourliness are hard to find in the informal settlements given the transient population and thus other demand drivers need to be identified. This emphasises the need to understand the status of household demand for sanitation improvements in the community to inform appropriate interventions. Only when the different stages of demand with the specific barriers and catalyst necessary for household adaption are identified, can any intervention be successful.

\section{Barriers and catalysts to demand for improved sanitation}

The key factors that influence the demand for improved sanitation are discussed here, including: environment and technology, social, economic and institutional. 


\section{Environment and technology}

337 The local environment and the technology are considered as the permanent hardware factors that can influence demand for improved sanitation, especially in informal settlements that are often located where there are no roads, water supply mains, sewer lines or other service networks. For economic reasons, the urban poor tend to settle on the most undesirable pieces of land with inadequate services to meet their basic needs, however environmental issues remain of concern to them and their choice of the technology will vary from households to communities (Solo et al. 1993).

Although a range of technologies are available along the sanitation supply chain, their selection is always based on preference, affordability and availability of materials (Katukiza et al. 2012). Yet some technologies may not be appropriate in informal settlements due to technical standards, regulations, land tenure system and limited space (Tumwebaze et al. 2013). Studies have shown that excreta disposal systems, packaged and delivered as low-cost "safe sanitation", but not matching the sanitation needs of the community may neither be appropriate nor used, and cannot therefore be sustained beyond the life of the project (Joshi et al. 2011). Kulabako et al. (2010) notes that key issues hindering sanitation improvements in typical informal settlements in Kampala include environmental issues, with low-lying terrain combined with a high water table and limited space which limits technology options to mainly traditional pit latrines.

The development of appropriate sanitation technologies for slum settlers should assimilate the specific needs of the intended users to create demand (Muwuluke 2007), otherwise the global declaration on the human right to water and sanitation for all (COHRE 2009) may not be realised.

\section{Social}

361 Social and cultural factors such as gender, religion and culture affect individuals' attitudes to waste generation and management (De Bruijne et al. 2007). The incentive for an individual to demand improved sanitation comes from a number of social behavioural characteristics of community and not merely awareness of public health or environmental degradation (Bracken et al. 2007). As an example, a study by Outlaw et al. (2007) noted that the high sanitation coverage in south-western Uganda was largely attributed to the cultural beliefs of the region because it is culturally abhorrent for a household not to have a latrine facility. 
Understanding community behaviour helps to integrate special factors in the sanitation management framework and change their behaviour to increase demand (Isunju et al. 2011). Behaviour change interventions are needed, not only to move people from open defecation to using a toilet, but also to encourage more hygienic use of facilities (Peal et al. 2010).

Social change requires an enabling environment in the form of political, economic, social, communication and cultural (Duhaime et al. 1985); all to instil the discipline that change may require. This has been demonstrated by a positive relationship between improvements in education, health and hygiene awareness and the demand for sanitation facilities, whereby households with members who had a higher level of literacy were most likely to demand and adopt safer methods of excreta disposal than those with low levels of literacy (WSP 2004).

Social marketing and community participation can influence sanitation demand by identifying and bringing together all stakeholders in the sector to integrate positive social traits in planning and design of sanitation services for the community (Isunju et al. 2011).

\section{Economic}

Traditionally, sanitation has not received the priority it deserves because the socio-economic benefits have not been either widely recognised or communicated appropriately. Open defecation has been calculated to cost more per person than any other type of unimproved sanitation based on the time taken to find a safe or private location for defecation, the personal risk associated with the process, and the costs likely to be incurred to solve health and environmental problems related to open defecation (WSP 2011). Poor sanitation is estimated to cost Rwanda an equivalent of US $\$ 54$ million (0.9\% of the national GDP), Kenya US \$324 million (0.9\% of the national GDP) each year (WSP 2012).

While strategies are being devised to finance sanitation in informal settlements through micro and meso-financing institutions like loans, group saving schemes, revolving funds, grants, public private partnerships (Trémolet 2012); demand must exist before people can even start to think of using the financing opportunities. The fundamental issue is the low priority residents in informal settlements give to sanitation, compared to other household needs and not only poverty (Isunju et al. 2011).

\section{Institutional}

400 During colonial times in Africa, households were forced by chiefs to dig pit latrines under 401 threat of jail, primarily during disease outbreaks, while missionaries preached to their 
congregations on how good hygiene was godly (WSP 2004; Jain 2011). In post-colonial times, the middle classes settle in the formal settlements with services provided by the state and have less health risks to sanitation-related diseases than low-income groups (Chaplin 1999) in the informal settlements.

Planning for sanitation services has not been locally specific but rather based on standard designs, or outsiders' judgments about what people need and ought to pay and not what the community wants (Altaf 1994; Varley et al. 1996; Robbins 2007). This supply-driven approach excludes large sections of the population from active participation and access to basic urban services (Chaplin 1999). The exclusion has been worsened by institutional weakness in sanitation service provision that stem from a lack of coordination, low capacity and insufficient resources (Mukuluke and Ngirane-Katashaya 2006).There is therefore need for reform in the institutional arrangement to be local specific by incorporating demand information in the planning of public services that considers household preferences and priorities (Anjum Altaf and Hughes 1994).

Review of the environmental, technological, social, financial and institutional factors that influence the demand for improved sanitation highlights the complexity of the process a household goes through to reach a point of expressing intent to install or upgrade to an improved sanitation facility. How the demand is measured is important to give the right picture of the type of intervention required in low-income informal settlements.

\section{Assessing demand for improved sanitation}

Demand assessment is a measurement of the level to which particular services are needed by individuals and the community. In this section, different sanitation demand assessment methodologies are reviewed so as to recommend an appropriate approach for low-income informal settlements.

Whilst there is a general consensus on the need to be demand-responsive (Parry-Jones 1999), there are different views on how demand is interpreted and assessed; which may give a wrong picture of the situation (Van der Hoek et al. 2010). Different professionals understand and assess demand according to their disciplines. Economists measure demand as a willingness to pay using the Contingent Valuation Method (CVM) e.g. Whittington et al. (1993), engineers measure demand as number and type of facilities relative to the population of a community, while social scientists measure demand using Participatory Rapid Appraisal (PRA) and relative demand based on community meetings (Parry-Jones 1999). Individually these different approaches do not take into consideration the positive attributes of the other 
disciplines and several scholars have suggested mixed methods that can ideally take care of all. Davis and Whittington (1998) compared two methodologies in a study undertaken in Lugazi, Uganda to assess the demand for water supply and sanitation services. In this study, both household surveys and community meetings were used however; the researchers could not conclusively draw a line on which is most appropriate and rather recommended the use of both methods. On the other hand, Jenkins and Scott's (2007) study using household surveys, generalised for rural and peri-urban selected sample households with children less than 5 years but interviewed only mothers.

In an attempt to address the social and cultural factors together with the habitual economic and technical aspects, Tiberghien et al. (2011) in their approach, rely on qualitative research tools to identify critical influences on sanitation development. Use of only qualitative methods does not wholly assess demand (Johnson et al. 2007).

A hybrid choice model that incorporates a set of latent attitudinal variables and explains how the demographic factors within a household influence choice show a clear cognitive process that influences sanitation adoption (Santos et al. 2011). However, the model only gives emphasis on choice of sanitation technology, which is just a single stage in the demand process. This leaves out a number of other influencing factors along the sanitation demand process, according to Jenkins and Scott (2007). The gap therefore still remains for the different disciplines to assess and integrate the results to give a realistic estimate of levels of demand for improved sustainable sanitation in informal settlements.

Review of the demand assessment methodologies in the literature highlights the need to consider the complexity of the sanitation demand process and unique characteristics of informal settlements. This requires that the assessment views sanitation demand from more than one theory and look at sanitation as both a household and community issue. The different theories employ specific tools to assess demand, and to better understand and interpret results from the different tools used on various stakeholders; using a multidisciplinary team of researchers can enhance the quality of results.

A multi-disciplinary team study to understand the barriers and catalysts for sanitation demand in low-income informal settlements in three study cities reports that proportions of households that are at the different stages of demand: "no preference", "preference", "intent", "choice" and "already installed" varied across the stages and the cities. The report also indicates that the variations relate to the geophysical and socio-economic characteristic of the settlements (Charles and Okurut 2013). The finding demonstrates the importance of multidisciplinary research in assessing demand for improved sanitation in informal settlements. In 
these settlements, sanitation coverage is still low compared to the average for urban areas but these areas harbour more than $60 \%$ of the urban populace in sub-Saharan Africa (UNHABITAT 2011). Involving a multi-disciplinary team and using mixed methods takes care of the biases that can be realised when using only quantitative or qualitative research methods, as well as the attributes of the different disciplines of knowledge in understanding the different aspects of demand. In addition, the multi-disciplinary mixed method assessment approach should be case specific in geographical areas of similar characteristics (urban, rural or peri-urban) and take into consideration the socio-economic, environmental, technological and institutional factors.

\section{Conclusion}

Sanitation improvement is crucial in low-income informal settlements to realise good health and sustainable livelihood amidst increasing pressure on scarce resources. This can only be achieved when efforts are put into increasing demand (Davis and Whittington 1998; Murray and Ray 2010; Tiberghien et al. 2011) for preferred service before identification of the appropriate soft and hardware sanitation solutions required (Pattanayak et al. 2009).

Demand for improved sanitation is complex and as it develops through preference, intention and choice, is influenced by environment, technology, social, financial and institutional factors. Proper assessment requires a better understanding of the influence of these factors within the population of study. Due to the complexity of household demand for improved sustainable sanitation and the uniqueness of low-income informal settlements, the authors argue that the assessment should involve a multi-disciplinary team and use of mixed methods to understand and evaluate the local demand from the different disciplinary perspectives.

This review reveals that sufficient skills and tools are important requirements to adequately assess sanitation demand in informal settlements, and points to the need for further research to adopt a multi-disciplinary research team to use mixed methods in identifying strategies for enhancing demand and hence increase access to improved sanitation in low-income informal settlements. The multi-disciplinary-mixed method assessment should look at the household preference for a better sanitation facility, their intent (how soon they plan) to install / improve or have made a choice of the appropriate technology option and, willingness and ability to pay within a specific period of say 12 months. This ensures that the demand measured is informed and real from all perspectives, for the sustainability of any hardware interventions. Only when the different stages of demand with the specific barriers 
504

505

506

507

508

509

510

511

512

513

514

515

516

517

518

519

520

521

522

523

524

525

526

527

528

529

530

531

532

533

534

535

536

537

538

539

540

541

542

543

544

545

546

547

548

549

550

551

552

and catalysts necessary for household adaption are identified, can the interventions be successful.

\section{References}

Ajzen, I. 2002. Perceived Behavioral Control, Self-Efficacy, Locus of Control, and the Theory of Planned Behavior1. Journal of applied social psychology 32(4): 665-83.

Ajzen, I. 2006. Behavioral Interventions Based on the Theory of Planned Behavior. Theory of Planned Behavior (TPB). pp. 6.

Altaf, M. A. 1994. Household demand for improved water and sanitation in a large secondary city: Findings from a study in Gujranwala, Pakistan. Habitat International 18(1): 45-55.

Anjum Altaf, M. and J. A. Hughes. 1994. Measuring the demand for improved urban sanitation services: Results of a contingent valuation study in Ouagadougou, Burkina Faso. Urban studies 31(10): 1763.

Bracken, P., A. Wachtler, A. Panesar, and J. Lange. 2007. The road not taken: how traditional excreta and greywater management may point the way to a sustainable future. Water Science \& Technology: Water Supply 7(1): 219-27.

Bunton, R., S. Murphy, and P. Bennett. 1991. Theories of behavioural change and their use in health promotion: some neglected areas. Health Education Research 6(2): 153-62.

Chaplin, S. E. 1999. Cities, sewers and poverty: India's politics of sanitation. Environment and Urbanization 11(1): 145-58.

Charles, K. and K. Okurut. 2013. Identifying barrier and catalysts to improved sanitation in informal settlements in East Africa: Poster presentation. Water and Health Conference: Where Science Meets Policy. University of North Carolina-ChapelHill, USA: UNC.

Clark, R. and S. W. Gundry. 2004. The prominence of health in donor policy for water supply and sanitation: A review. Journal of water and health 2(3): 157-59.

COHRE. 2009. The significance of human rights in MDG-based policy making on water and sanitation: An application to Kenya, South Africa, Ghana, Sri Lanka and Laos. Right to Water Programme. pp. 33. Geneva.

COHRE, WaterAid, S. and, and UN-HABITAT. 2008. Sanitation: A human rights imperative. pp. 50. Geneva.

Creswell, J. W. and V. L. P. Clark. 2007. Designing and conducting mixed methods research: Wiley Online Library.

Curtis, V. A., N. Garbrah-Aidoo, and B. Scott. 2007. Ethics in Public Health Research. Journal Information 97(4).

Davis, J. and D. Whittington. 1998. "Participatory" Research for Development Projects: A Comparison of the Community Meeting and Household Survey Techniques. Economic Development and Cultural Change 47(1): 73-94.

De Bruijne, G., M. Geurts, and B. Appleton. 2007. Sanitation for All?: IRC International Water and Sanitation Centre.

Duhaime, C. P., R. McTavish, and C. A. Ross. 1985. Social marketing: an approach to third-world development. Journal of Macromarketing 5(1): 3-13.

Evans, B. 2004. Whatever Happened to Sanitation?-Practical steps to achieving a core Development Goal. MDG Task Force background paper.

Evans, B. and S. Tremolet. 2010. Output-based Aid and Sustainable Sanitation.

Foppen, J. W. and F. Kansiime. 2009. SCUSA: integrated approaches and strategies to address the sanitation crisis in unsewered slum areas in African mega-cities. Reviews in Environmental Science and Biotechnology 8(4): 305-11.

Glanz, K. and D. B. Bishop. 2010. The role of behavioral science theory in development and implementation of public health interventions. Annual review of public health 31: 399-418. 
Günther, I., A. Horst, C. Lüthi, H.-J. Mosler, B. C. Niwagaba, and I. Tumwebaze K. 2011. Research evidence for policy. Where do Kampala's poor "go"? Urban sanitation conditions in Kampala's low-income areas. pp. 4. Kampala: Makerere University.

Günther, I., B. C. Niwagaba, C. Lüthi, A. Horst, H.-J. Mosler, and I. Tumwebaze K. 2012. Research for policy 2. When is shared sanitation improved sanitation? The correlation between number of users and toilet hygiene. pp. 4. Kampala: Makerere University.

Hogrewe, W., S. D. Joyce, and E. A. Perez. 1993. Unique challenges of improving peri-urban sanitation: US Agency for International Development.

Hutton, G., L. Haller, and J. Bartram. 2007. Global cost-benefit analysis of water supply and sanitation interventions. Journal of water and health 5(4): 481-502.

Isunju, J., K. Schwartz, M. Schouten, W. Johnson, and M. Van Dijk. 2011. Socio-economic aspects of improved sanitation in slums: A review. Public Health.

Jain, N. 2011. Getting Africa to meet the sanitation MDG. WSP.

Jenkins, M. W. and B. Scott. 2007. Behavioral indicators of household decision-making and demand for sanitation and potential gains from social marketing in Ghana. Social Science \& Medicine 64(12): 2427-42.

Jenkins, M. W. and S. Sugden. 2006. Rethinking sanitation: Lessons and innovation for sustainability and success in the new millennium. Human Development Occasional Papers (1992-2007).

Johnson, R. B., A. J. Onwuegbuzie, and L. A. Turner. 2007. Toward a definition of mixed methods research. Journal of mixed methods research 1(2): 112-33.

Joshi, D., B. Fawcett, and F. Mannan. 2011. Health, hygiene and appropriate sanitation: experiences and perceptions of the urban poor. Environment and Urbanization 23(1): 91-111.

Kar, K. and R. Chambers. 2008. Handbook on community-led total sanitation: Plan UK London.

Katukiza, A., M. Ronteltap, C. Niwagaba, J. Foppen, F. Kansiime, and P. Lens. 2012. Sustainable sanitation technology options for urban slums. Biotechnology advances.

Kulabako, R. N., M. Nalubega, E. Wozei, and R. Thunvik. 2010. Environmental health practices, constraints and possible interventions in peri-urban settlements in developing countries-a review of Kampala, Uganda. International Journal of Environmental Health Research 20(4): 23157.

Kvarnström, E., ., J. McConville, P. Bracken, M. a. Johansson, and M. Fogde. 2011. The sanitation ladder - a need for a revamp? Journal of Water, Sanitation and Hygiene for Development 1(01): 9.

Lüthi, C., J. McConville, and E. Kvarnström. 2010. Community-based approaches for addressing the urban sanitation challenges. International Journal of Urban Sustainable Development 1(1-2): 4963.

Lüthi, C., J. McConville, A. Norström, A. Panesar, R. Ingle, D. Saywell, and T. Schütze. Year. Rethinking Sustainable Sanitation for the Urban Environment. In, edited by, pp.

Mara, D., J. Lane, B. Scott, and D. Trouba. 2010. Sanitation and health. PLoS medicine 7(11): e1000363.

Montano, D. E. and D. Kasprzyk. 2008. Theory of reasoned action, theory of planned behavior, and the integrated behavioral model. Health behavior and health education: Theory, research, and practice 4: 67-95.

Moraes, L., J. A. Cancio, S. Cairncross, and S. Huttly. 2003. Impact of drainage and sewerage on diarrhoea in poor urban areas in Salvador, Brazil. Transactions of the Royal Society of Tropical Medicine and Hygiene 97(2): 153-58.

Mosler, H. J. 2012. A systematic approach to behavior change interventions for the water and sanitation sector in developing countries: a conceptual model, a review, and a guideline. International Journal of Environmental Health Research 22(5): 431-49.

Mukherjee, N. and N. Shatifan. 2010. The CLTS story in Indonesia. Empowering communities, transforming institutions, furthering decentralization. Institute of Development Studies. Accessible: http://www. communityledtotalsanitation. org/resource/clts-storyindonesia- 
empowering-communities-transforminginstitutions-furthering-decentrali (accessed November 2011).

Mukuluke, J. and G. Ngirane-Katashaya. 2006. Exploring sustainability of sanitation systems: Socialcultural acceptability analysis of technology options for Kampala's peri-urban areas using multicriteria decision analysis. Journal of Engineering and Applied Sciences 1(4): 445-55.

Murray, A. and I. Ray. 2010. Commentary: Back-End Users: The Unrecognized Stakeholders in Demand-Driven Sanitation. Journal of Planning Education and Research 30(1): 94-102.

Muwuluke, J. Z. 2007. Planning Sustainable Sanitation Systems: A case of human excreta management in peri-urban areas of Kampala. Department of Civil and Environmental Engineering. pp. 223. Kampala: Makerere University.

Mwanzia, P. and W. Misati. 2013. Total sanitation in Nakuru slum. 36th WEDC International Conference. pp. 6. Nakuru, Kenya: WEDC, Loughborough University.

Outlaw, T., M. Jenkins, and B. Scott. 2007. Opportunities for Sanitation Marketing in Uganda. USAID Hygiene Improvement Project. pp. 62. Washingto, DC: USAID.

Parry-Jones, S. 1999. Optimising the selection of demand assessment techniques for water supply and sanitation projects. Project task.

Paterson, C., D. Mara, and T. Curtis. 2007. Pro-poor sanitation technologies. Geoforum 38(5): 901-07.

Pattanayak, S. K., C. Poulos, J. C. Yang, S. R. Patil, and K. J. Wendland. 2009. Of taps and toilets: quasiexperimental protocol for evaluating community-demand-driven projects. Journal of water and health 7(3): 434.

Peal, A., B. Evans, and C. van der Voorden. 2010. Hygiene and Sanitation Software: An Overview of Approaches.

Prochaska, J. O. and W. F. Velicer. 1997. The transtheoretical model of health behavior change. American journal of health promotion 12(1): 38-48.

Robbins, P. T. 2007. The reflexive engineer: perceptions of integrated development. Journal of International Development 19(1): 99-110.

Roma, E., C. Buckley, B. Jefferson, and P. Jeffrey. 2010. Assessing users' experience of shared sanitation facilities: A case study of community ablution blocks in Durban, South Africa. Water Sa 36(5).

Samanta, B. and C. Van Wijk. 1998. Criteria for successful sanitation programmes in low income countries. Health policy and planning 13(1): 78-86.

Santos, A. C., J. A. Roberts, M. L. Barreto, and S. Cairncross. 2011. Demand for sanitation in Salvador, Brazil: A hybrid choice approach. Social Science \& Medicine.

Schertenleib, R. Year. Principles and Implications of Household Centered Approach in Environmental Sanitation. In First International Conference on Ecological Sanitation, edited by, pp. 28-34.

Solo, T. M., E. Perez, and S. Joyce. 1993. Constraints in providing water and sanitation services to the urban poor: US Agency for International Development.

Tiberghien, J., P. Robbins, and S. F. Tyrrel. 2011. Reflexive assessment of practical and holistic sanitation development tools using the rural and peri-urban case of Mexico. Journal of Environmental Management 92(3): 457-71.

Tilley, E., SANDEC, W. Supply, and S. C. Council. 2008. Compendium of sanitation systems and technologies: Swiss Federal Institute of Aquatic Science and Technology.

Trémolet, S. 2012. Small-scale finance for water and sanitation. pp. 72. London, UK: EU Water Initiative - Finance Working Group (EUWI-FWG).

Trémolet, S., P. Koslky, and E. Perez. 2010. Financing on-site sanitation for the poor: a global six country comparative review and analysis. Washington DC: World Bank, Water and Sanitation Programme.

Tumwebaze, I. K., C. G. Orach, C. Niwagaba, C. Luthi, and H.-J. Mosler. 2013. Sanitation facilities in Kampala slums, Uganda: users' satisfaction and determinant factors. International Journal of Environmental Health Research 23(3): 191-204. 
UN-HABITAT. 2003. The challenge of slums: global report on human settlements. United Nations Human Settlements Programme.

UN-HABITAT. 2011. State of the World's cities 2010/2011: Bridging the urban divide. London: UNHABITAT.

UN. 2011. The Millennium Development Goals Report 2011. We can end poverty by 2015. New York. UNICEF/WHO. 2009. Diarrhea: Why children are still dying and what can be done. pp. 68. Geneva.

Van Der Geest, S. 2002. The night-soil collector: Bucket latrines in Ghana. Postcolonial Studies: Culture, Politics, Economy 5(2): 197-206.

Van der Hoek, W., B. Evans, J. Bjerre, M. Calopietro, and F. Konradsen. 2010. Measuring progress in sanitation.

Van Wyk, R. 2009. A review of Sanitation and Health promotion as part of sanitation delivery programmes to informal settlements (City of Cape Town).

Varley, R. C. G., M. M. Yacoob, and S. Smith. 1996. Beyond participation: locally based demand for environmental health in peri-urban areas: Environmental Health Project.

Waterkeyn, J. and S. Cairncross. 2005. Creating demand for sanitation and hygiene through Community Health Clubs: A cost-effective intervention in two districts in Zimbabwe. Social Science \& Medicine 61(9): 1958-70.

Waterkeyn, J. A. and A. J. Waterkeyn. 2013. Creating a culture of health: hygiene behaviour change in community health clubs through knowledge and positive peer pressure. Journal of Water, Sanitation and Hygiene for Development 3(2): 144-55.

Whittington, D., D. T. Lauria, A. M. Wright, K. Choe, J. A. Hughes, and V. Swarna. 1993. Household Demand for Improved Sanitation Services in Kumasi, Ghana: A Contingent Valuation Study. Water Reources Research 29(6): 1539-60.

WHO/UNICEF. 2008. Joint Monitoring Programme (JMP) for Water Supply and Sanitation. Improved / unimproved sanitation facilities. Switzerland: WHO/UNICEF.

WHO/UNICEF. 2010. JMP for Water Supply and Sanitation: Estimates for Improved Sanitation Facilities, Uganda 2010. pp. 15. Geneva.

WHO/UNICEF. 2012. Progress on Drinking Water and Sanitation. The WHO/UNICEF Joint Monitoring Programme for Water Supply and Sanitation. WHO/UNICEF. New York: JMP.

WSP. 2001. Identifying Demand Drivers for Sanitation Technologies. wsp.

WSP. 2004. Sanitation and Hygiene in Kenya: Lessons on What Drives Demand for Improved Sanitation. Nairobi: Water and Sanitation Programm - Africa (WSP).

WSP. 2011. Estimating the economic impacts of poor sanitation in African. Water and Sanitation Program (WSP). pp. 2. Washington DC: WSP - World Bank.

WSP. 2012. Economic impacts of poor sanitation in African. Kenya loses KES 27 billion annually due to poor sanitation. pp. 6. 